Departamento de Zoologia Médica e Parasitologia

Diretor: Prof. Dr. Z. Vaz

\title{
NOTA PRÉVIA SOBRE O EMPREGO DA ÁGUA OXIGENADA NO TRATAMENTO DAS HELMINTOSES DO CÃO DOMÉSTICO $\left(^{*}\right)$
}

POR

\section{T. L. Araujo e L. M. Guimarães \\ Assistentes}

Em 1934 BuTz e LALANDE estudaram o comportamento da água oxigenada sobre exemplares de Ascaris lumbricoides, verme comum, do porco e do homem. As experiências desses autores foram feitas "in vitro" e deram como resultados a verificação da toxicidade do composto sobre o parasita. Tres anos após ScHWARTz \& PORTER retomaram o assunto, mas desta vez experimentaram o efeito do peróxido de hidrogênio não mais "in vitro", porem "in vivo". Usaram ratos e cães infestados por vermes intestinais, conseguindo a remoção ora parcial ora total dos mesmos, com a introdução por meio de sonda gástrica da solução do novo vermífugo em experiência. Dois trabalhos posteriores respectivamente de MAGRANE \& MAgrane e de Whitney publicados em 1939 relatam resultados animadores no tratamento das verminoses intestinais do cão.

Da leitura desses trabalhos adveiu-nos a idéia de experimentar o emprego da água oxigenada como vermífugo e começamos a empregá-la em nosso laboratório com resultados satisfatórios.

\begin{tabular}{|c|c|c|c|c|}
\hline CãoN.o & Idade & Sexo & $\begin{array}{l}\text { Exames de fezes antes do } \\
\text { tratamento }\end{array}$ & $\begin{array}{l}\text { Exames de } \\
\text { fezes depois do } \\
\text { tratamento }\end{array}$ \\
\hline 1 & 8 meses & fem. & A. caninum - T. canis & negativo \\
\hline 2 & 7 anos & mase. & A. caninum & $"$ \\
\hline 3 & 1 ano & $"$ & A. caninum - T. canis & $"$ \\
\hline 4 & $1 \frac{1}{2}$ ano & $"$ & D. caninum - T. canis & $"$ \\
\hline 5 & 2 anos & " & T. eanis & $"$ \\
\hline 6 & 3 anos & fem. & T. vulpis - A. caninum & $"$ \\
\hline 7 & Indet. & masc. & A. caninum - D. caninum & $"$ \\
\hline 8 & 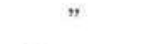 & " & A. caninum & $"$ \\
\hline 9 & 2 anos & $"$ & A. caninum & $"$ \\
\hline 10 & Indet. & $"$ & A. caninum & $"$ \\
\hline
\end{tabular}

(*) Comunicado à Sociedade de Biologia de São Paulo em 8-12-41. 
Resumimos no quadro anterior os resultados obtidos em 10 cães, parasitados por uma ou mais de uma das seguintes espécies: Ancylostoma caninum, Toxocara canis, Dipyllidium caninum, Trichuris vulpis. Nesses animais foram feitos exames de fezes, diretos e de enriquecimento, antes e depois de serem submetidos ao tratamento. Este consiste na administração lenta, por via retal, de uma solução a $1,5 \%$ de água oxigenada em quantidade necessária para provocar o vomito. Essa quantidade varia naturalmente conforme o peso do animal.

$\mathrm{O}$ assunto presentemente ainda em estudos, será oportunamente publicado como tese por um de nos. 